\title{
High-Performance Steel Bars and Fibers as Concrete Reinforcement for Seismic-Resistant Frames
}

\author{
Andres Lepage, ${ }^{1}$ Hooman Tavallali, ${ }^{2}$ Santiago Pujol, ${ }^{3}$ and Jeffrey M. Rautenberg ${ }^{4}$ \\ ${ }^{1}$ Department of Architectural Engineering, The Pennsylvania State University, 104 Engineering Unit A, University Park, \\ PA 16802, USA \\ ${ }^{2}$ Leslie E. Robertson Associates, 40 Wall Street, 23rd Floor, New York, NY 10005, USA \\ ${ }^{3}$ School of Civil Engineering, Purdue University, 550 Stadium Mall Drive, West Lafayette, IN 47907, USA \\ ${ }^{4}$ Wiss, Janney, Elstner Associates, 2000 Powell Street, Suite 1650, Emeryville, CA 94608, USA
}

Correspondence should be addressed to Andres Lepage, lepage@psu.edu

Received 12 December 2011; Accepted 13 February 2012

Academic Editor: Rajesh Prasad Dhakal

Copyright (C) 2012 Andres Lepage et al. This is an open access article distributed under the Creative Commons Attribution License, which permits unrestricted use, distribution, and reproduction in any medium, provided the original work is properly cited.

\begin{abstract}
Experimental data are presented for six concrete specimens subjected to displacement reversals. Two specimens were reinforced longitudinally with steel bars Grade 410 (60 ksi), two with Grade 670 (97ksi), and two with Grade 830 (120ksi). Other experimental variables included axial load ( 0 or $\left.0.2 f_{c}^{\prime} A_{\mathrm{g}}\right)$ and volume fraction of hooked steel fibers $(0$ or $1.5 \%)$. All transverse reinforcement was Grade 410, and the nominal concrete compressive strength was $41 \mathrm{MPa}$ (6 ksi). The loading protocol consisted of repeated cycles of increasing lateral displacement reversals (up to $5 \%$ drift) followed by a monotonic lateral push to failure. The test data indicate that replacing conventional Grade-410 longitudinal reinforcement with reduced amounts of Grade-670 or Grade-830 steel bars did not cause a decrease in usable deformation capacity nor a decrease in flexural strength. The evidence presented shows that the use of advanced high-strength steel as longitudinal reinforcement in frame members is a viable option for earthquake-resistant construction.
\end{abstract}

\section{Introduction}

For many years, the earthquake-resistant design of reinforced concrete structures in the USA has been dominated by the use of steel reinforcement with specified yield strength, $f_{y}$, of $410 \mathrm{MPa}(60 \mathrm{ksi})$. Although higher values of $f_{y}$ are allowed for non-seismic applications, $f_{y}$ has been limited to $550 \mathrm{MPa}$ (80 ksi) since the 1971 edition of ACI 318 [1]. Current version of ACI 318 [2] maintains the above limits but allows designs with $f_{y}$ of $690 \mathrm{MPa}$ (100 ksi) only if used for confining reinforcement.

The terms advanced high-strength steel (AHSS) [3] or ultrahigh strength steel (UHSS) [4] are used to designate high-performance steel bars with a yield strength in excess of $550 \mathrm{MPa}(80 \mathrm{ksi})$ and a fracture strain, $\varepsilon_{s u}$, of $6 \%$ or more measured in a 203-mm (8-in.) gage length. Figure 1 shows representative stress-strain curves of both conventional Grade 410 and AHSS steels. After the introduction of ASTM A1035 in 2004 [5] and their acceptance as confining reinforcement in the 2005 version of ACI 318, there has been growing interest in AHSS bars. ASTM A706 [6] introduced its new Grade 550 in 2009 and it is likely that new ASTM designations with higher grades will follow. However, there is a paucity of test data describing the behavior of concrete members reinforced with AHSS bars as longitudinal reinforcement.

A series of experiments was designed to determine the deformation capacity of AHSS-reinforced concrete frame members subjected to displacement reversals $[7,8]$. Specimens with high-performance fiber-reinforced concrete (HPFRC) were included. HPFRC is defined here as a class of fiber-reinforced concrete that shows strain hardening after first cracking [9].

The use of high-strength steel bars as reinforcement in concrete elements has the potential to reduce problems associated with congested reinforcement cages and concrete placement, as well as reduce costs associated with the shipment and placement of reinforcing steel. The cost savings 


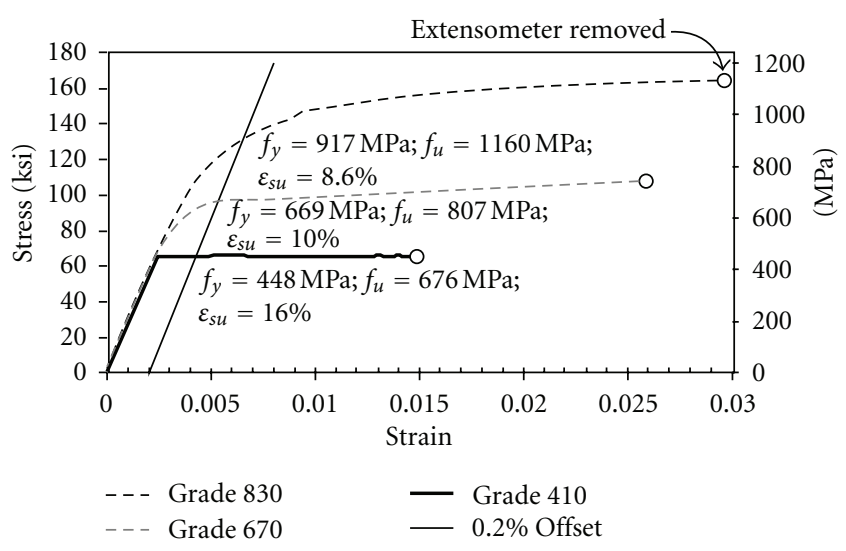

FIGURE 1: Representative tensile properties of reinforcing bars, $1 \mathrm{ksi}$ $=6.9 \mathrm{MPa}$.

are nearly proportional to the increase in yield strength used in design.

\section{Background}

There is no evidence in the USA of reinforced concrete structures built or rehabilitated using AHSS longitudinal and transverse reinforcement and designed to take full advantage of $f_{y}$ in excess of $550 \mathrm{MPa}(80 \mathrm{ksi})$ for stresses induced by combined shear, flexure, and axial forces. This underutilization is predominantly due to the shortage of experimental data and the limitations contained in existing building codes.

The use of high-strength reinforcement in concrete columns was first considered in the early 1930s by Richart and Brown [10] in a series of laboratory tests on columns with circular cross sections and spiral reinforcement. The column tests showed that longitudinal bars with yield strength close to $690 \mathrm{MPa}$ (100 ksi) were fully effective in columns resisting concentric axial loads. The spiral reinforcement allowed the concrete in the core of the column to develop compressive strains large enough for the longitudinal reinforcement to reach its yield point.

Later, in the 1960s, the experimental work at the PCA laboratories [11] led to a series of reports titled "High-strength bars as concrete reinforcement." In Part 5 of the PCA series [12], similar observations to those by Richart and Brown [10] were made for columns reinforced with spirals. But in the case of tied columns with rectangular sections, the PCA report noted: "If the specified yield point of longitudinal reinforcement in tied columns is to be developed at ultimate strength of the columns, then it is necessary that the yield point be reached at or before a strain of 0.003 in./in." [12].

Todeschini et al. [13] confirmed the PCA findings. As a consequence, ACI 318-63 [14] introduced strength design provisions with limits on the specified yield strength of reinforcing bars. ACI 318-63 Section 1505 had a limit of $520 \mathrm{MPa}$ (75 ksi) on the specified yield strength of compression reinforcement and $410 \mathrm{MPa}$ (60 ksi) for tension reinforcement (unless special tests satisfied crack control requirements, in which case $520 \mathrm{MPa}$ was permitted). The limits on the specified yield strength in Section 1505 of the 1963 Code were justified in the commentary [15] by stating: "High strength steels frequently have a strain at yield strength or yield point in excess of the 0.003 assumed for the concrete at ultimate. The requirements of Section 1505 are to adjust to this condition. The maximum stress in tension of 60,000 psi without test is to control cracking."

In 1971, ACI 318 [1] increased the limit on yield strength of reinforcement to $550 \mathrm{MPa}(80 \mathrm{ksi})$. The limit in current USA design provisions [2] is still $550 \mathrm{MPa}$ ( $80 \mathrm{ksi}$ ). Section 9.4 of ACI 318-11 [2] requires "The values of $f_{y}$ and $f_{y t}$ used in design calculations shall not exceed 80,000 psi, except for prestressing steel and for transverse reinforcement in 10.9.3 and 21.1.5.4." The exception only applies to transverse reinforcement used for confinement, where $f_{y t}$ up to $690 \mathrm{MPa}$ (100 ksi) is allowed. For earthquake-resistant design, Section 21.1.5 of ACI 318-11 allows only longitudinal reinforcement with $f_{y}$ of $410 \mathrm{MPa}(60 \mathrm{ksi})$ or lower.

If the use of AHSS bars as primary reinforcement is to be considered for practical use, the issues related to concrete compressive strain and crack control must be addressed. A method of addressing these issues is to add fibers to the concrete mix to control crack widths and to enhance the usable compressive strain of concrete. High tensile and compressive strain capacities are attainable by concrete reinforced with dispersed fibers. Recent developments in high-performance fiber-reinforced cementitious composites include new formulations of concrete matrices and fibers to achieve strain hardening behavior with fiber volume contents in the range of $1 \%$ to $2 \%$ [16].

Studies on the compressive properties of cementitious composites have shown that the introduction of fibers into the matrix delays spalling of the cover and increases the load capacity and the ductility of columns over that of comparable reinforced concrete (RC) specimens [17]. Several research projects have explored the application of fiberreinforced composites in earthquake-resistant construction, as summarized by Parra-Montesinos [9]. Results from these studies revealed HPFRC to be effective in increasing shear strength and deformation capacity in members subjected to cycles of large inelastic deformations, but none of these studies incorporated AHSS reinforcement. The experiments presented below were designed to address this gap.

\section{Experiments}

A collaborative experimental program between The Pennsylvania State University and Purdue University was aimed at studying the behavior of AHSS-reinforced concrete frame members subjected to displacement reversals. Beam tests were conducted at Penn State by Tavallali [7], and column tests were conducted at Purdue by Rautenberg [8]. The scope of this paper is limited to specimens defined by the following ranges of test variables:

(i) nominal yield strength of the longitudinal reinforcement, $f_{y}=410,670$, or $830 \mathrm{MPa}(60,97$, or $120 \mathrm{ksi})$;

(ii) applied axial force, $P=0$ or $0.2 f_{c}^{\prime} A_{\mathrm{g}}$;

(iii) volume fraction of hooked steel fibers, $V_{f}=0$ or $1.5 \%$. 

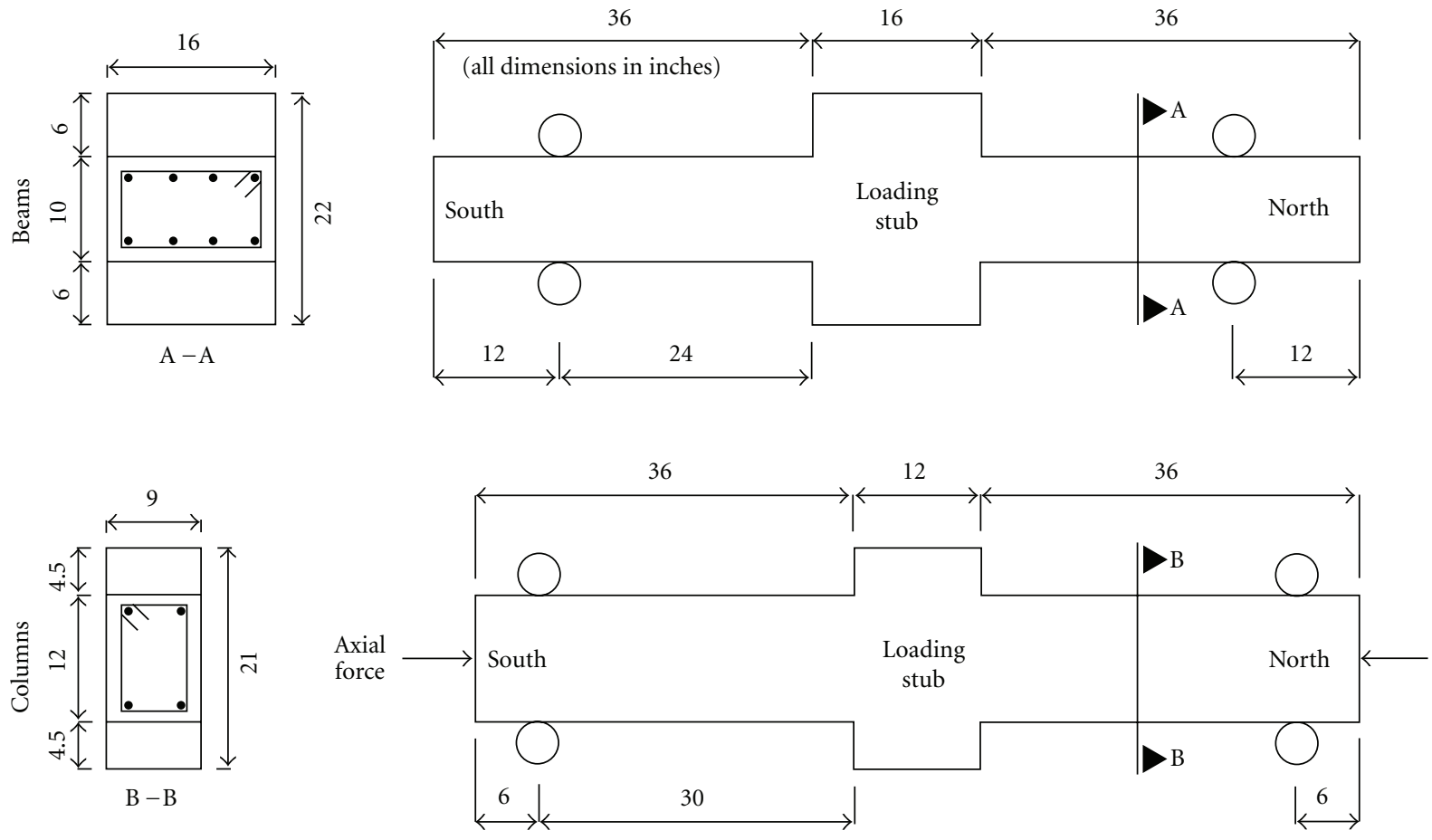

Figure 2: Geometry of test specimens, $1 \mathrm{in} .=25.4 \mathrm{~mm}$.

All transverse reinforcement was Grade 410 and the nominal compressive strength of concrete was $41 \mathrm{MPa}$ (6 ksi). The layout of the longitudinal reinforcement was symmetrical with identical top and bottom layers. Table 1 shows a summary of the specimens considered.

The geometry of typical beam and column specimens is shown in Figure 2. The specimens consisted of two beams (or columns) connected to a central stub. The specimens were loaded through the central stub so that they were in singlecurvature bending. Each beam (or column) was intended to represent a cantilever with the central stub acting as the base of the cantilever. The shear span-to-effective depth ratio for all specimens was 3 . In the column specimens, the axial force was kept constant throughout the loading protocol.

The amount of longitudinal reinforcement in each specimen was chosen so that the nominal flexural strength of all specimens was nearly identical. Thus, specimen CC3.3-20 with Grade-410 steel used about twice the amount of longitudinal reinforcement as used in specimens UC1.6-20 and UC-1.6-20F with Grade-830 steel. A similar relationship exists between specimens CC4-X, UC4-X, and UC2-F. The shear stress corresponding to the probable moment, $M_{p r}$, calculated according to ACI 318-11 [2] was approximately $0.42 \sqrt{f_{c}^{\prime}, \mathrm{MPa}}\left(5 \sqrt{f_{c}^{\prime}, \mathrm{psi}}\right)$ for the beams and $0.58 \sqrt{f_{c}^{\prime}, \mathrm{MPa}}\left(7 \sqrt{f_{c}^{\prime}, \mathrm{psi}}\right)$ for the columns. The longitudinal bars were all continuous through the central stub and had sufficient embedment length to develop $1.25 f_{y}$ at the faces of the stub. The embedment lengths satisfy the requirements for development lengths in Chapter 12 of ACI 318-11.

HPFRC specimens UC2-F and CC-1.6-20F had 1.5\% volume fraction of Dramix RC-80/30-BP hooked steel fibers, with length-to-diameter ratio of 80 and a length of $30 \mathrm{~mm}$ (1.2 in.). The fibers had a nominal tensile strength of $2300 \mathrm{MPa}(330 \mathrm{ksi})$. These fibers are commercially available and manufactured by Bekaert Corporation. The maximum aggregate size in the concrete matrix of specimens CC4$\mathrm{X}, \mathrm{UC} 4-\mathrm{X}, \mathrm{UC2}-\mathrm{F}$, and UC-1.6-20F, was limited to $13 \mathrm{~mm}$ (0.5 in.), less than half the fiber length. Maximum aggregate size for specimens CC-3.3-20 and UC-1.6-20 was $25 \mathrm{~mm}$ (1 in.).

Specimens CC4-X, UC4-X, CC-3.3-20, and UC-1.6-20, without fibers, used Grade-410 transverse reinforcement spaced at $d / 4$, in compliance with Chapter 21 of ACI 318-11 [2]. Specimens UC2-F and UC-1.6-20F, cast using HPFRC, used Grade-410 transverse reinforcement spaced at approximately $d / 2$. The spacing in the HPFRC specimens was increased to account for the enhanced shear strength and confinement provided by fibers.

The drift ratio history applied to each specimen follows the protocol of FEMA 461 [18] described in Table 2. The drift ratio was defined as the lateral displacement of the specimen divided by the shear span, corrected for the rotation of the loading stub. Two cycles at each drift target were applied to the stub at increasing amplitudes. After step 12, the displacement was increased monotonically until failure (defined here as a reduction in the lateral-load resistance of more than $25 \%$ from the peak value).

\section{Measured Response}

The measured data for shear versus drift ratio of the controlling end of the specimens (north or south) are presented for the 12 steps ( 24 cycles) of the loading protocol. 
TABLE 1: Description of test specimens.

\begin{tabular}{|c|c|c|c|c|c|c|c|c|c|c|c|}
\hline \multirow[b]{2}{*}{ Specimen } & & \multirow[b]{2}{*}{$\begin{array}{c}\text { Axial load } \\
A_{\mathrm{g}} f_{c}^{\prime}\end{array}$} & \multirow[b]{2}{*}{$\begin{array}{c}f_{c}^{\prime} \\
\operatorname{MPa}(k s i)\end{array}$} & \multicolumn{5}{|c|}{ Longitudinal reinforcement ${ }^{\mathrm{a}}$} & \multicolumn{3}{|c|}{ Transverse reinforcement ${ }^{\mathrm{a}}$} \\
\hline & & & & $\begin{array}{c}\text { Bars per } \\
\text { layer }^{\mathrm{a}}\end{array}$ & $\begin{array}{c}d_{b} \\
\mathrm{~mm}(\text { in.) }\end{array}$ & $\begin{array}{c}f_{y}{ }^{\mathrm{b}} \\
\mathrm{MPa}(\mathrm{ksi})\end{array}$ & $\begin{array}{c}f_{u} \\
\mathrm{MPa}(\mathrm{ksi})\end{array}$ & $\begin{array}{c}\mathcal{E}_{s u} \\
\%\end{array}$ & $\begin{array}{c}s \\
\mathrm{~mm}(\text { in. })\end{array}$ & $\begin{array}{c}d_{b} \\
\mathrm{~mm}(\text { in. })\end{array}$ & $\begin{array}{c}f_{y t}^{\mathrm{b}} \\
\operatorname{MPa}(\mathrm{ksi})\end{array}$ \\
\hline \multicolumn{12}{|c|}{ Beams $^{c}$} \\
\hline$\# 1$ & CC4-X & 0 & $41(6.0)$ & 4 & $22(7 / 8)$ & $448(65)$ & $676(98)$ & 15.9 & $51(2.0)$ & $9.5(3 / 8)$ & $469(68)$ \\
\hline$\# 2$ & UC4-X & 0 & $43(6.2)$ & 4 & $18(0.71)^{\mathrm{d}}$ & $669(97)$ & $807(117)$ & 10.4 & $51(2.0)$ & $9.5(3 / 8)$ & $469(68)$ \\
\hline$\# 3$ & UC2-F & 0 & $44(6.4)$ & 4 & $18(0.71)^{\mathrm{d}}$ & $669(97)$ & $807(117)$ & 10.4 & $102(4.0)$ & $9.5(3 / 8)$ & $469(68)$ \\
\hline \multicolumn{12}{|c|}{ Columns ${ }^{\mathrm{e}}$} \\
\hline$\# 4$ & CC-3.3-20 & 0.20 & $54(7.8)$ & 3 & $22(7 / 8)$ & $441(64)$ & $634(92)$ & 20.3 & $64(2.5)$ & $9.5(3 / 8)$ & $428(62)$ \\
\hline$\# 5$ & UC-1.6-20 & 0.21 & $43(6.3)$ & 2 & $19(3 / 4)^{\mathrm{f}}$ & $917(133)$ & $1160(168)$ & 8.6 & $64(2.5)$ & $9.5(3 / 8)$ & $434(63)$ \\
\hline \#6 & UC-1.6-20F & 0.19 & $51(7.4)$ & 2 & $19(3 / 4)^{\mathrm{f}}$ & $917(133)$ & $1160(168)$ & 8.6 & $114(4.5)$ & $9.5(3 / 8)$ & $434(63)$ \\
\hline
\end{tabular}

${ }^{a}$ Bar layout is symmetrical with identical top and bottom layers. Transverse reinforcement consists of single rectilinear hoops spaced at $s=d / 4$ (specimens \#1, $\# 2$, \#4, and \#5) or $s \approx d / 2$ (specimens \#3 and \#6 with fibers).

${ }^{\mathrm{b}}$ Defined using the $0.2 \%$-offset method.

${ }^{c}$ Beams tested at The Pennsylvania State University: $b=406 \mathrm{~mm}$ ( $\left.16 \mathrm{in}.\right), h=254 \mathrm{~mm}$ (10 in.), and $d=203 \mathrm{~mm}$ (8 in.).

${ }^{\mathrm{d}}$ Provided by SAS Stressteel.

${ }^{e}$ Columns tested at Purdue University: $b=229 \mathrm{~mm}$ (9 in.), $h=305 \mathrm{~mm}$ (12 in.), $d=254 \mathrm{~mm}$ (10 in.).

${ }^{\mathrm{f}}$ Provided by MMFX Technologies.

TABLE 2: Loading protocol.

\begin{tabular}{lcccccccccccc}
\hline Step $^{\mathrm{a}}$ & 1 & 2 & 3 & 4 & 5 & 6 & 7 & 8 & 9 & 10 & 11 & 12 \\
\hline Drift ratio, \% & 0.15 & 0.20 & 0.30 & 0.40 & 0.60 & 0.80 & 1.0 & 1.5 & 2.0 & 3.0 & 4.0 & 5.0 \\
\hline
\end{tabular}

${ }^{a}$ Two symmetrical cycles of loading in each step, with equal drifts in the positive and negative direction, as recommended in FEMA 461 [18].

Beams are shown in Figure 3 and columns in Figure 4. The figures do not include the data associated with the monotonic push to failure (after step 12 in Table 2). The maximum measured shears and drift ratios are presented in Table 3 .

4.1. Beam Specimens. Specimen CC4-X is the control RC beam specimen compliant with the provisions for special moment frame beams in Chapter 21 of ACI 318-11 [2]. All reinforcing bars were Grade 410, see Table 1 . The widths of flexural cracks exceeded $0.4 \mathrm{~mm}$ (0.016 in.) at a drift ratio of $0.8 \%$. First yield of the longitudinal reinforcement was measured between $0.76 \%$ and $1.17 \%$ with a mean of $0.97 \%$ (Table 4). The peak shear force of $242 \mathrm{kN}$ (54.4 kip) was reached during the final push at a drift ratio in excess of $10 \%$, an indication of a stable hysteretic behavior throughout the test, see Figure 3(a).

Specimen UC4-X had similar properties to specimen CC4-X with the exception that it was reinforced longitudinally with Grade-670 bars, see Table 1. Compared with specimen CC4-X, specimen UC4-X showed a reduced postcracking stiffness and increased yield deformation, see Figures 3(a) and 3(b). Due to the reduced amount of longitudinal reinforcement in specimen UC4-X, a smaller drift ratio $(0.6 \%)$ was associated with crack widths exceeding $0.4 \mathrm{~mm}$ (0.016 in.), as opposed to $0.8 \%$ in specimen CC4$\mathrm{X}$. First yield of the longitudinal reinforcement occurred between $1.36 \%$ and $1.68 \%$ with a mean of $1.49 \%$ (Table 4 ). The peak shear force of $234 \mathrm{kN}$ (52.5 kip) was reached at a drift ratio of $2.6 \%$. During the final push, the peak shear was
$215 \mathrm{kN}$ (48.3 kip) at a drift ratio of 7.1\%. Specimen UC4-X exceeded $10 \%$ drift without failure.

Specimen UC2-F had similar properties to specimen UC4-X except that it was cast using HPFRC. Spacing of the transverse reinforcement was increased to $d / 2$ to investigate the effects of fibers. Crack widths exceeded $0.4 \mathrm{~mm}$ (0.016 in.) at a drift ratio of $1 \%$, a significant improvement compared to the other beam specimens. The drift ratio at first yield of the longitudinal reinforcement varied between $1.19 \%$ and $1.37 \%$ with a mean of $1.28 \%$ (Table 4 ). The south beam deviated from the loading protocol at the first cycle of step 9 because the north beam was controlling through step 8, see Figure 3(c). During the first cycle of step 9, the specimen reached a peak shear force of $273 \mathrm{kN}$ (61.4 kip). During the final push, the peak shear was $223 \mathrm{kN}$ (50.2 kip) at a drift ratio of $6.3 \%$. Specimen UC2-F exceeded $10 \% \mathrm{drift}$ without failure.

The reduction of transverse reinforcement by $50 \%$ in specimen UC2-F did not have a negative impact on its behavior. HPFRC was effective in enhancing the shear capacity and confinement. However, crack openings concentrated in a single flexural crack near the face of the stub at drift ratios exceeding 3\%. The presence of this wide flexural crack resulted in the accumulation of residual strains in longitudinal bars crossing the crack. Figures 5 and 6 show specimens UC4-X and UC2-F at the end of the second cycle at 5\% drift (end of step 12). Figures 7 and 8 show the strain measurements in the longitudinal bars of these specimens at face of the central stub during steps 10 and 11 . The strain values measured at the same location for the same drift ratios are 
TABLE 3: Maximum measured shear force and drift ratio.

\begin{tabular}{|c|c|c|c|c|c|c|c|}
\hline \multirow[t]{2}{*}{ Specimen } & & \multicolumn{2}{|c|}{$\begin{array}{c}V_{\max }^{\mathrm{a}} \\
\mathrm{kN} \text { (kip) }\end{array}$} & \multicolumn{2}{|c|}{$\begin{array}{l}v_{\max }{ }^{2} \\
\mathrm{MPa}(\mathrm{psi})\end{array}$} & \multicolumn{2}{|c|}{$\begin{array}{c}\theta_{\max }^{c} \\
\%\end{array}$} \\
\hline & & + & - & + & - & + & - \\
\hline \multicolumn{8}{|c|}{ Beams } \\
\hline$\# 1$ & CC4-X & $242(54.4)$ & $217(48.8)$ & $0.46(5.5)$ & $0.41(4.9)$ & $>10$ & 5.0 \\
\hline$\# 2$ & UC4-X & $234(52.5)$ & $226(50.7)$ & $0.43(5.2)$ & $0.42(5.0)$ & $>10$ & 5.1 \\
\hline$\# 3$ & UC2-F & $273(61.4)$ & $232(52.1)$ & $0.50(6.0)$ & $0.42(5.1)$ & $>10$ & 5.1 \\
\hline \multicolumn{8}{|c|}{ Columns } \\
\hline$\# 4$ & CC-3.3-20 & $252(56.6)$ & $266(59.9)$ & $0.59(7.1)$ & $0.63(7.5)$ & 5.1 & 5.0 \\
\hline$\# 5$ & UC-1.6-20 & $228(51.3)$ & $228(51.3)$ & $0.60(7.2)$ & $0.60(7.2)$ & 5.2 & 4.8 \\
\hline \#6 & UC-1.6-20F & $260(58.4)$ & $247(55.5)$ & $0.63(7.5)$ & $0.60(7.2)$ & 5.3 & 5.4 \\
\hline
\end{tabular}

${ }^{a}$ Maximum measured shear force during the loading protocol (Table 2).

${ }^{\mathrm{b}}$ Shear stress calculated using $V_{\max } /(b d)$, expressed as a fraction of $\sqrt{f_{c}^{\prime}}$, where $b, d$, and $f_{c}^{\prime}$ are given in Table 1 .

${ }^{c}$ Maximum drift ratio reached while maintaining a shear force not less than $75 \%$ of $V_{\max }$ in the same direction of loading. Maximum reported value includes the drift ratio attained during the final monotonic push in the positive direction.

TABLE 4: Measured yield point.

\begin{tabular}{|c|c|c|c|c|c|c|c|c|}
\hline Specimen & & & & $\begin{array}{c}\text { Shear }^{\mathrm{a}} \\
\mathrm{kN} \text { (kip) }\end{array}$ & Mean & $\begin{array}{c}\text { Drift ratio } \\
\%\end{array}$ & Mean & $\begin{array}{l}\text { Secant stiffness } \\
\text { kN/mm (kip/in.) }\end{array}$ \\
\hline \multirow{12}{*}{ Beams } & \multirow{4}{*}{$\# 1$} & \multirow{4}{*}{ CC4-X } & South + & $206(46.3)$ & \multirow{4}{*}{$174(39.2)$} & 0.93 & \multirow{4}{*}{0.97} & \multirow{4}{*}{$29.5(168)$} \\
\hline & & & South - & $176(39.6)$ & & 1.03 & & \\
\hline & & & North + & $180(40.5)$ & & 1.17 & & \\
\hline & & & North - & $134(30.2)$ & & 0.76 & & \\
\hline & \multirow{4}{*}{$\# 2$} & \multirow{4}{*}{ UC4-X } & South + & $202(45.3)$ & \multirow{4}{*}{$198(44.6)$} & 1.52 & \multirow{4}{*}{1.49} & \multirow{4}{*}{$21.8(125)$} \\
\hline & & & South - & $194(43.7)$ & & 1.38 & & \\
\hline & & & North + & $199(44.7)$ & & 1.68 & & \\
\hline & & & North - & $198(44.6)$ & & 1.36 & & \\
\hline & \multirow{4}{*}{$\# 3$} & \multirow{4}{*}{ UC2-F } & South + & $202(45.4)$ & \multirow{4}{*}{$196(44.1)$} & 1.37 & \multirow{4}{*}{1.28} & \multirow{4}{*}{$25.1(144)$} \\
\hline & & & South - & 185 (41.7) & & 1.26 & & \\
\hline & & & North + & $218(49.1)$ & & 1.29 & & \\
\hline & & & North - & $178(40.1)$ & & 1.19 & & \\
\hline \multirow{12}{*}{ Columns } & \multirow{4}{*}{$\# 4$} & \multirow{4}{*}{ CC-3.3-20 } & South + & $238(53.4)$ & \multirow{4}{*}{$244(54.8)$} & 0.67 & \multirow{4}{*}{0.78} & \multirow{4}{*}{$42.0(240)$} \\
\hline & & & South - & $252(56.7)$ & & 0.78 & & \\
\hline & & & North + & $242(54.4)$ & & 0.83 & & \\
\hline & & & North - & $243(54.7)$ & & 0.85 & & \\
\hline & \multirow{4}{*}{$\# 5$} & \multirow{4}{*}{ UC-1.6-20 } & South + & $-^{c}$ & \multirow{4}{*}{$208(46.7)$} & $-^{c}$ & \multirow{4}{*}{1.41} & \multirow{4}{*}{$20.2(115)$} \\
\hline & & & South - & 204 (45.9) & & 1.39 & & \\
\hline & & & North + & $210(47.3)$ & & 1.44 & & \\
\hline & & & North - & $209(47.0)$ & & 1.39 & & \\
\hline & \multirow{4}{*}{ \#6 } & \multirow{4}{*}{ UC-1.6-20F } & South + & $-^{c}$ & \multirow{4}{*}{$224(50.4)$} & - $^{\mathrm{c}}$ & \multirow{4}{*}{1.42} & \multirow{4}{*}{$21.6(123)$} \\
\hline & & & South - & $221(49.6)$ & & 1.28 & & \\
\hline & & & North + & $-^{c}$ & & $-^{c}$ & & \\
\hline & & & North - & $228(51.2)$ & & 1.55 & & \\
\hline
\end{tabular}

\footnotetext{
${ }^{a}$ Shear force measured at first yield of the longitudinal reinforcement. Top and bottom bars were instrumented with strain gages at the north and south faces of the central stub. The yield point is based on the value of $f_{y}$ reported in Table 1 .

${ }^{b}$ Secant stiffness to first yield of the longitudinal reinforcement. In columns, P-delta effects are removed.

${ }^{\mathrm{c}}$ Measurement not available.
} 


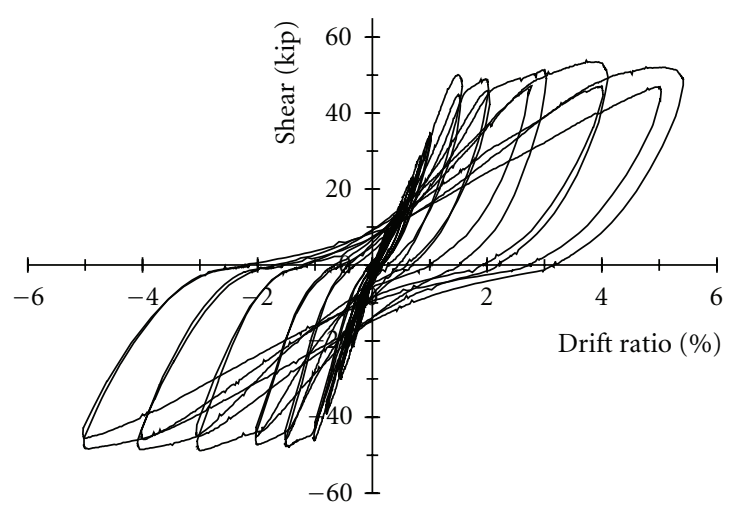

(a) Specimen CC4-X north

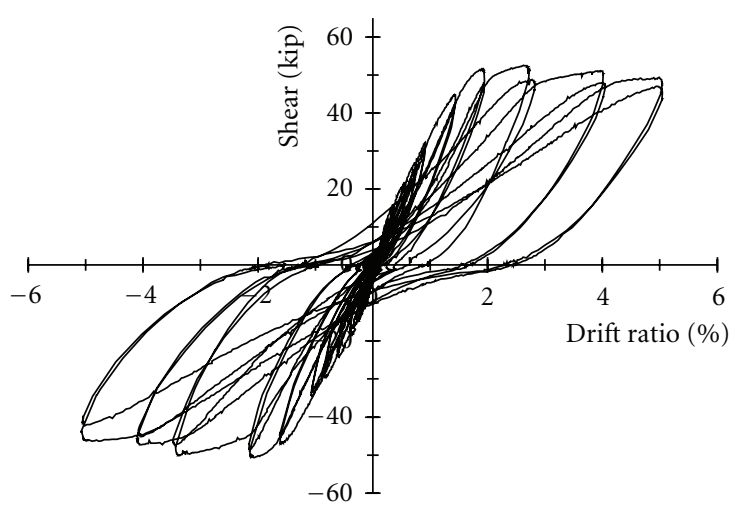

(b) Specimen UC4-X south

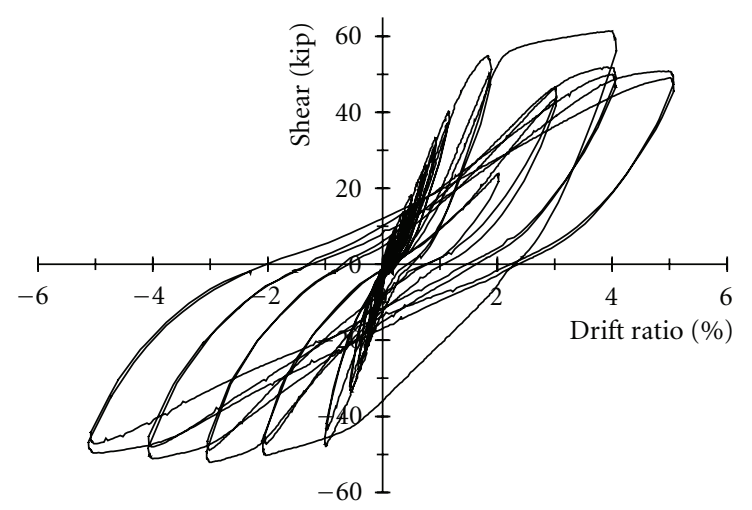

(c) Specimen UC2-F south

Figure 3: Measured shear versus drift ratio, beams ( $1 \mathrm{kip}=4.45 \mathrm{kN})$.

approximately 50\% larger in specimen UC2-F, an indication of higher strain concentration in the plastic hinge of the HPFRC specimen. As a result of strain accumulation, the longitudinal bars fractured at $11 \%$ drift in specimen UC2F, while similar bars in specimen UC4-X fractured at a drift ratio of $15 \%$. In any case, the beam specimens all reached drift ratios well in excess of what would be expected for a modern building structure subjected to strong ground motion.

4.2. Column Specimens. Specimen CC-3.3-20 is the control $\mathrm{RC}$ column specimen compliant with the provisions for special moment frame columns in Chapter 21 of ACI 318-11 [2]. All reinforcing bars were Grade 410, see Table 1. First yield of the longitudinal reinforcement was measured between $0.67 \%$ and $0.85 \%$ with a mean of $0.78 \%$ (Table 4 ). Figure 4 (a) shows the measured shear-drift response. The north column followed the loading protocol (Table 2) through the first cycle of step 12. During the second cycle to 5\% drift, the longitudinal bars buckled at a drift ratio of about $1 \%$. A plausible explanation for the failure of the specimen is that cracks on both sides of the specimen were still open at low drift ratios, and the axial load was carried predominantly by the longitudinal reinforcement, leading to bar buckling.

Specimen UC-1.6-20 had similar properties to specimen CC-3.3-20 with the exception that it was reinforced longitudinally with Grade- 830 bars using about half as much longitudinal reinforcement. Figure 4(b) shows the measured shear-drift response. Compared with specimen CC-3.3-20, specimen UC-1.6-20 showed reduced postcracking stiffness and increased yield deformation. First yield of the longitudinal reinforcement occurred between $1.39 \%$ and $1.44 \%$ with a mean of $1.41 \%$ (Table 4 ). The north column completed the first half-cycle to $5 \%$ drift, but the longitudinal bars buckled during the second half cycle at that drift ratio. Testing was continued, and the remaining longitudinal bars buckled at a drift ratio of about $2 \%$ during the second cycle to $5 \%$ drift. Again, a plausible explanation is that the longitudinal bars carried a larger fraction of the axial load at low drift ratios when cracks were still open.

Specimen UC-1.6-20F had similar properties to specimen UC-1.6-20, with the exception that the concrete matrix consisted of HPFRC. The spacing of the transverse reinforcement was nearly doubled to evaluate the influence of HPFRC in shear strength, confinement, and bar buckling. Figure 4(c) shows the measured shear-drift response. The drift ratio at first yield of the longitudinal reinforcement varied between $1.28 \%$ and $1.55 \%$ with a mean of $1.42 \%$ (Table 4), which is similar to the yield drift of specimen UC1.6-20, but the yield force in UC- $1.2-20 \mathrm{~F}$ was $8 \%$ greater.

The HPFRC column specimen was the only column (with axial load of $0.2 f_{c}^{\prime} A_{g}$ ) that successfully completed 


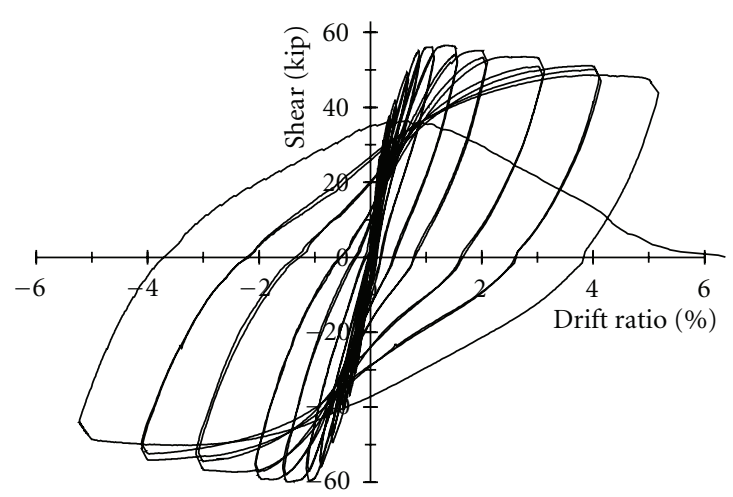

(a) Specimen CC-3.3-20 north

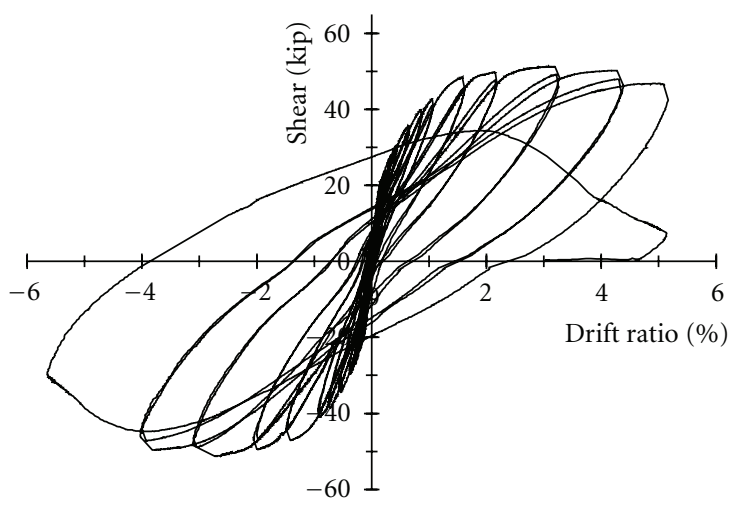

(b) Specimen UC-1.6-20 north

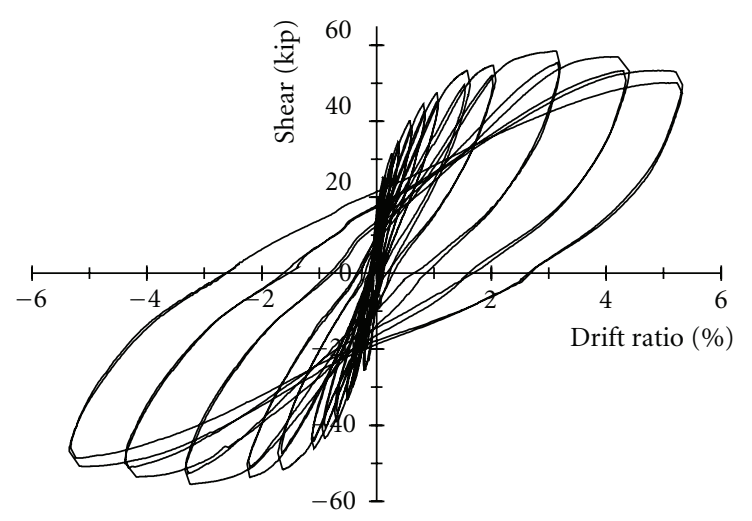

(c) Specimen UC-1.6-20F north

Figure 4: Measured shear versus drift ratio, columns $(1 \mathrm{kip}=4.45 \mathrm{kN})$.

the 12-step loading protocol. The fibers were effective in reducing the amount of spalling of the concrete cover and providing lateral support to the longitudinal reinforcement. Unlike specimens CC-3.3-20 and UC-1.6-20, the reinforcement in specimen UC-1.6-20F did not buckle. However, in the final push, one of the longitudinal bars fractured in tension at a drift of about 3\%. Adding fibers changed the mode of failure from buckling of the compression bars to fracture of the tension bars. It is important to note that the measured fracture strain, $\varepsilon_{s u}$, of the bars in specimen UC$1.6-20 \mathrm{~F}$ was $8.6 \%$ (Table 1 ), the lowest of the bars tested. To reduce the vulnerability of bar fracture, reinforcing bars with $\varepsilon_{s u}$ greater than $10 \%$ are recommended in HPFRC applications as suggested by the stable response of the beam specimens through drift ratios of $10 \%$. In any case, specimens reached drift ratios of $5 \%$ or greater, well in excess of what would be expected for a modern building structure subjected to strong ground motions.

\section{Stiffness Comparisons}

Stiffness characteristics for the test specimens are inferred from the measured shear versus drift curves (Figures 3 and 4) with special emphasis on secant stiffness to first yield, postyield stiffness, and unloading stiffness. The shear force and drift ratio associated with first yield of the longitudinal reinforcement are presented in Table 4 . The reported secant stiffness to first yield for each specimen corresponds to the average of the measured yield for the north and south ends of each specimen and for the positive and negative direction of loading (see Figure 9). For clarity, the measured response in Figure 9 only includes data through the end of step 8 controlled by the north beam. The yield points identified in Figure 9 were obtained from strain gages placed on longitudinal bars at the locations of maximum moment (at opposite faces of the loading stub). The yield strain was defined using $f_{y} / E_{s}$, where $f_{y}$ was based on the $0.2 \%$-offset method as reported in Table 1.

It is important to recognize that there is no consensus about the definition of yield displacement. The definition used here was chosen simply because it was convenient. It is clear that the $0.2 \%$-offset rule was not defined having estimation of hysteretic response in mind. It is also known that the displacement associated with strain-gage readings approaching the yield strain tends to be smaller than the displacement associated with yielding of the specimen [19].

5.1. Beam Specimens. The secant stiffness to first yield of specimen UC4-X was about $3 / 4$ of the stiffness of specimen CC4-X and about $7 / 8$ of the stiffness of specimen UC2-F 


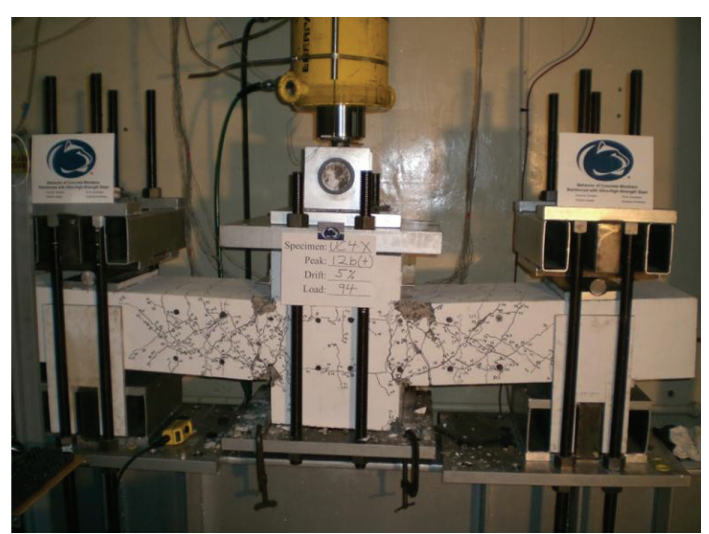

FIgURE 5: Specimen UC4-X at drift ratio of 5\%.

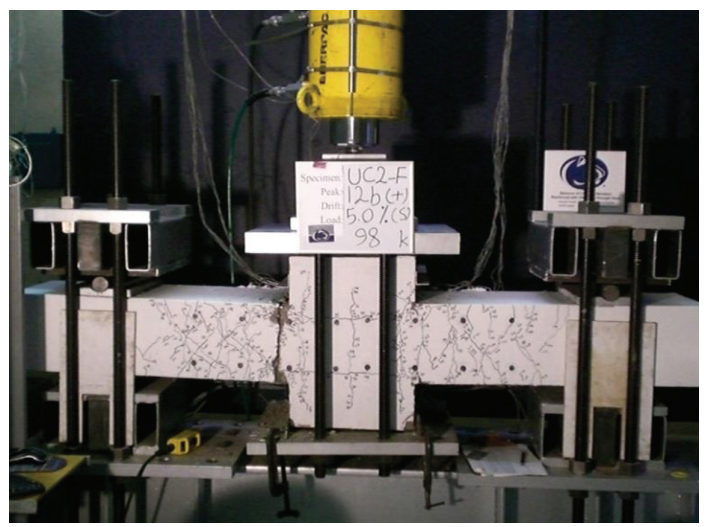

Figure 6: Specimen UC2-F at drift ratio of 5\%.

(see Table 4). After yielding, specimen CC4-X showed a small increase in flexural strength while specimen UC4-X had a nearly flat postyield shear-drift curve resembling the stress-strain curve of the rebar (Figure 1). The conventional Grade-410 bars are characterized by a tensile-strength-toyield-strength ratio $\left(f_{u} / f_{y}\right)$ of 1.5 , while the AHSS Grade670 bars have a ratio of 1.2. The hysteretic energy dissipated in specimen UC4-X during a given postyield hysteretic loop was smaller than the energy dissipated in the same cycle for specimen CC4-X. With the use of HPFRC in specimen UC2$\mathrm{F}$, the amount of energy dissipated increased when compared to specimen UC4-X. At each cycle, the secant slope of the shear-drift curve, measured from peak drift to zero shear (unloading stiffness), was about $20 \%$ higher in specimen UC2-F than in specimen UC4-X.

5.2. Column Specimens. The secant stiffness to first yield of specimens UC-1.6-20 and UC-1.6-20F was about $1 / 2$ of the stiffness of specimen CC-3.3-20, see Table 4. The effect of HPFRC on the stiffness of the column was small. After yielding, specimens UC-1.6-20 and UC-1.6-20F (with Grade- 830 bars) showed a small increase in flexural strength and reached peak shear near 3\% drift while specimen CC3.3-20 reached peak shear near $1.5 \%$ drift. The hysteretic

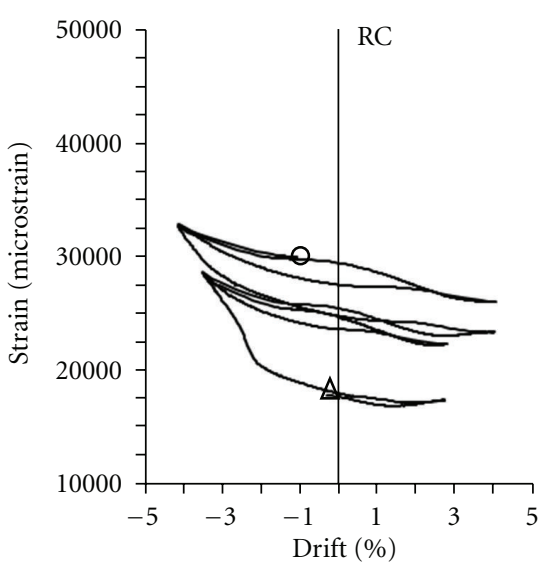

O End of step 11

$\Delta$ End of step 9

Figure 7: Top bar tensile strain at face of loading stub, specimen UC4-X south.

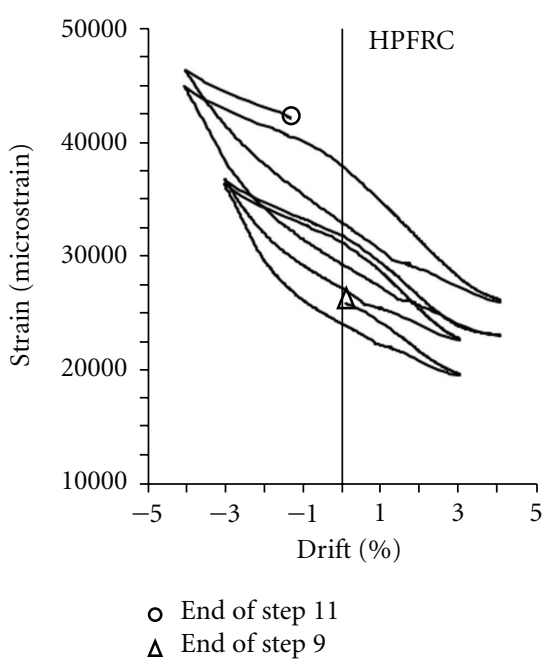

FIgURE 8: Top bar tensile strain at face of loading stub, specimen UC2-F south.

energy dissipated during a given postyield hysteretic loop was smaller in specimens UC-1.6-20 and UC-1.6-20F (with Grade-830 bars) than for specimen CC-3.3-20 (with Grade410 bars). At each cycle, the secant slope of the shear-drift curve of specimens UC-1.6-20 and UC-1.6-20F, measured from peak drift to zero shear (unloading stiffness), was about $1 / 2$ of that for specimen CC-3.3-20.

\section{Calculated Seismic Response}

The experimental results in Section 4 show that for the beams reinforced with Grade-670 bars, the secant stiffness to first yield is about 3/4 of that for beams reinforced with Grade410 bars, see Table 4 . For columns reinforced with Grade- 830 bars, the secant stiffness to first yield is about $1 / 2$ of that for columns reinforced with Grade-410 bars. 


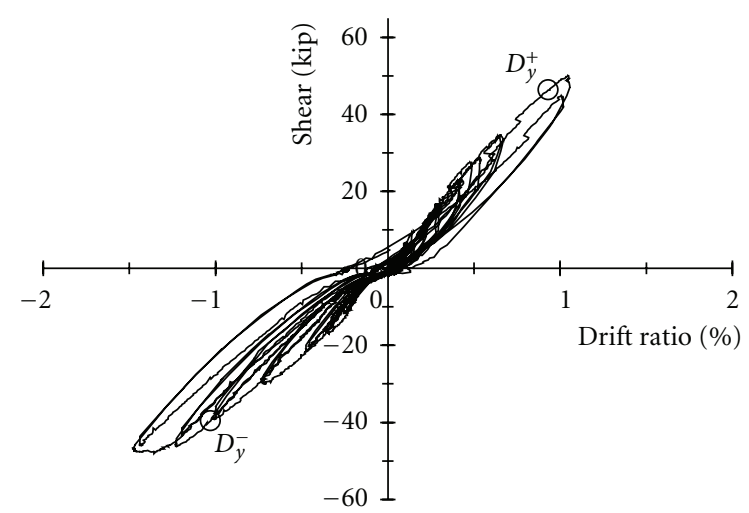

(a) Specimen CC4-X south

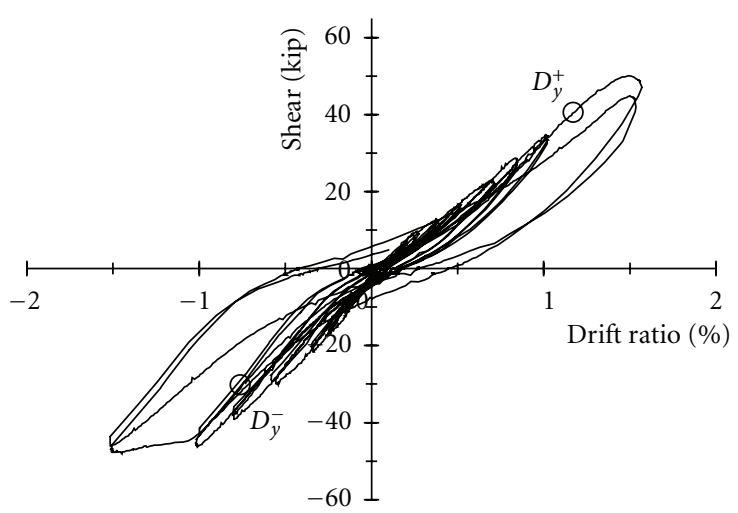

(b) Specimen CC4-X north

Figure 9: Measured yield points in specimen CC4-X $(1 \mathrm{kip}=4.45 \mathrm{kN})$.

This section investigates how changes in the hysteretic response of RC members, due to the use of Grade- 410 reinforcement versus AHSS reinforcement (Grade 670 or Grade 830), affect the displacement demand in single-degreeof-freedom (SDOF) systems subjected to strong ground motions.

6.1. Properties of SDOF Systems. Three groups of six SDOF systems were selected. Each group represented reinforced concrete with a different type of reinforcement: Grade 410, Grade 670, and Grade 830. The Grade- 410 systems included three different periods of vibration $(T=0.6,0.9$, and $1.2 \mathrm{~s})$ and two strength ratios $(S R=1 / 3$ and $1 / 6)$. The strength ratio measures the ratio of the maximum force induced in a nonlinear SDOF system to the maximum force induced in a linear SDOF system. The target design spectrum, defining the linear-response demand, was based on $S_{D S}=1.0$ and $S_{D 1}=0.75$ as defined in ASCE/SEI 710 [20]. The properties of the SDOF systems considered are described in Table 5. Note that the Grade-670 and Grade-830 systems were patterned after the Grade- 410 systems using equivalent strength but with reduced stiffness as indicated by the difference in periods of vibration.

The force-displacement relations that characterize the SDOF systems are based on a simplified version of the Takeda hysteresis model [21], as shown in Figure 10. The model is defined by four parameters: the initial stiffness, $K_{y}$; the yield strength, $V_{y}$; the postyield stiffness, $K_{p y}$ and the unloading stiffness coefficient, $\alpha$. The modified Takeda model adopted here is based on a bilinear primary curve where the initial uncracked stiffness is ignored. This model can produce displacement waveforms very similar to that of more elaborate models [22]. The stiffness of the model is $K_{y}$, until the force exceeds the yield force $V_{y}$. The postyield stiffness is defined here as $5 \%$ of the initial stiffness. The stiffness $K_{u}$, during unloading from a point of maximum displacement (see Figure 10) is defined using

$$
K_{u}=K_{y}\left(\frac{D_{y}}{D_{\max }}\right)^{\alpha}
$$

A value of $\alpha=0.4$ is assigned to the Grade- 410 systems, and $\alpha=0.5$ is used to represent the Grade- 670 and Grade- 830 systems. The selected values are in agreement with the beam data presented in Figure 11, where for CC4-X the value of $\alpha$ approaches 0.4 for $D_{\max } / D_{y}$ between 4 and 5, while for AHSS-reinforced members the value of $\alpha$ is about 0.5 for $D_{\max } / D_{y}$ between 3 and 4 . The data in Figure 11 correspond to the average value of $\alpha$ (average for the positive and negative direction of loading) derived from the available measured response during the second cycles of steps 9 through 12 (see Table 2). The data associated with steps 9 and 10 were excluded for specimen UC2-F because during these steps the test deviated from the loading protocol. The value of $\alpha$ for specimen UC2-F was similar to that of UC4-X because at step 11 localized fiber pullout had occurred. Figure 11 suggests that the value of $\alpha$ for columns is nearly insensitive to the steel grade.

The viscous damping assigned to the SDOF systems is based on a damping coefficient of $5 \%$, assumed constant (mass-proportional damping) during the calculated nonlinear response. The $\beta$-Method by Newmark [23], with $\beta=1 / 6$, was used to evaluate the dynamic response.

6.2. Ground Motions and Scaling. The SDOF systems were subjected to the suite of 10 strong-motion acceleration records described in Table 6 . The selected ground motions are representative of major earthquakes in the United States. These earthquake records were obtained from the Center for Engineering Strong Motion Data (CESMD) [24]. The CESMD is part of the California Strong Motion Instrumentation Program (CSMIP) and may be found at http://www.strongmotioncenter.org. Although the recorded raw data are made available by the CESMD, the data used here correspond to the processed (corrected) ground accelerations.

Each of the earthquake records was scaled linearly to a peak ground velocity of $508 \mathrm{~mm} / \mathrm{s}$ (20 in./s). The $5 \%$ damped linear-response acceleration spectra for the 10 records after scaling are presented in Figure 12. The figure shows that the average of the spectral accelerations, in 
TABLE 5: Properties of SDOF systems considered.

\begin{tabular}{|c|c|c|c|c|c|}
\hline $\begin{array}{l}\text { System }^{\mathrm{a}} \\
\mathrm{MPa}(\mathrm{ksi})\end{array}$ & No. & $\begin{array}{c}\text { Period of } \\
\text { vibration }^{\mathrm{b}} \\
T, \mathrm{~s} \\
\end{array}$ & $\begin{array}{c}\text { Spectral acceleration } \\
\text { coefficient }^{\mathrm{c}} \\
S_{A}, \mathrm{~g} \\
\end{array}$ & $\begin{array}{l}\text { Strength } \\
\text { ratio }^{\mathrm{d}} \\
S R\end{array}$ & $\begin{array}{c}\text { Yield strength } \\
\text { coefficient }^{\mathrm{e}} \\
C_{y} \\
\end{array}$ \\
\hline \multirow{6}{*}{ Grade $410(60)$} & 1 & \multirow[b]{2}{*}{0.60} & \multirow[b]{2}{*}{1.00} & $1 / 3$ & 0.33 \\
\hline & 2 & & & $1 / 6$ & 0.17 \\
\hline & 3 & \multirow[b]{2}{*}{0.90} & \multirow[b]{2}{*}{0.83} & $1 / 3$ & 0.28 \\
\hline & 4 & & & $1 / 6$ & 0.14 \\
\hline & 5 & \multirow[b]{2}{*}{1.20} & \multirow[b]{2}{*}{0.63} & $1 / 3$ & 0.21 \\
\hline & 6 & & & $1 / 6$ & 0.10 \\
\hline \multirow{6}{*}{ Grade 670 (97) } & 7 & \multirow[b]{2}{*}{0.69} & \multirow[b]{2}{*}{1.00} & & 0.33 \\
\hline & 8 & & & & 0.17 \\
\hline & 9 & \multirow[b]{2}{*}{1.04} & \multirow[b]{2}{*}{0.72} & & 0.28 \\
\hline & 10 & & & & 0.14 \\
\hline & 11 & \multirow{2}{*}{1.39} & \multirow{2}{*}{0.54} & & 0.21 \\
\hline & 12 & & & & 0.10 \\
\hline \multirow{6}{*}{ Grade 830 (120) } & 13 & \multirow{2}{*}{0.85} & \multirow[b]{2}{*}{0.88} & & 0.33 \\
\hline & 14 & & & & 0.17 \\
\hline & 15 & \multirow[b]{2}{*}{1.27} & \multirow[b]{2}{*}{0.59} & & 0.28 \\
\hline & 16 & & & & 0.14 \\
\hline & 17 & \multirow[b]{2}{*}{1.70} & \multirow[b]{2}{*}{0.44} & & 0.21 \\
\hline & 18 & & & & 0.10 \\
\hline
\end{tabular}

${ }^{a}$ Grade-670 and Grade- 830 systems represent equivalent alternatives to Grade-410 systems. All systems target identical strength; however, the stiffness of Grade- 670 or Grade- 830 systems is 0.75 or 0.50 times the stiffness of Grade-60 systems. In all cases, the postyield stiffness was defined as $5 \%$ of the initial stiffness.

${ }^{\mathrm{b}}$ Target periods of vibration for Grade-410 systems are set to $0.6,0.9$, and $1.2 \mathrm{~s}$ for a unit mass, from which the stiffness is derived. The stiffness of Grade-670 or Grade- 830 systems is 0.75 or 0.50 times that of Grade- 410 systems.

${ }^{\mathrm{c}}$ Linear-response acceleration (divided by $g$ ) of a $5 \%$-damped SDOF system of period $T$. It is defined using $S_{A}=S_{D 1} / T \leq S_{D S}$, where $S_{D S}=1.0$ and $S_{D 1}=0.75$, refer to ASCE/SEI 7-10 [20].

${ }^{d}$ Yield force, $V_{y}$, of nonlinear SDOF system (of initial period $T$ ) divided by the force induced in a 5\%-damped linear SDOF system of period $T$.

${ }^{\mathrm{e}} C_{y}=S_{A} \cdot S R=V_{y} / W$, where $S R$ is the strength ratio and $S_{A}$ is the spectral acceleration coefficient obtained from the design spectrum $(5 \%$ damping coefficient) for a system of period $T$. The value of $C_{y}$ corresponds to the yield strength, $V_{y}$, divided by the weight, $W$, of the SDOF system.

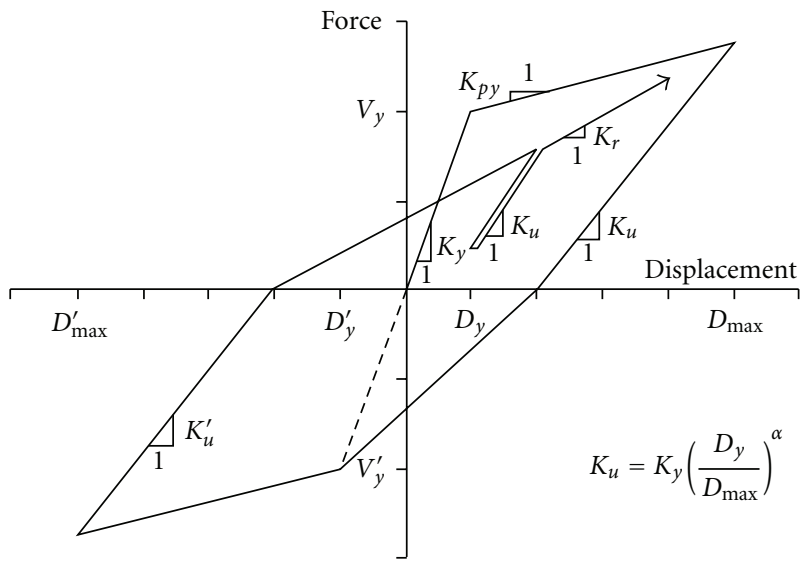

FIGURE 10: Hysteresis model considered.

the period range between 0.6 and $1.2 \mathrm{~s}$, is within $10 \%$ of the idealized target spectrum based on $S_{D S}=1.0$ and $S_{D 1}=0.75$ as defined in ASCE/SEI 7-10 [20].

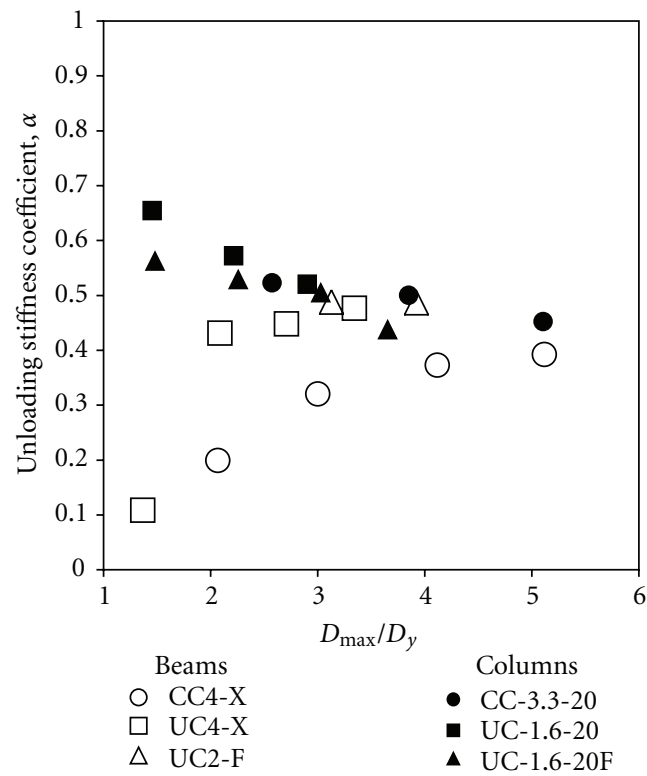

FIGURE 11: Unloading stiffness coefficient for test specimens. 
TABLE 6: Ground motions considered.

\begin{tabular}{|c|c|c|c|c|c|c|}
\hline Station $^{\mathrm{a}}$ & Earthquake & Magnitude & $\begin{array}{l}\text { Epicentral distance } \\
\mathrm{km}\end{array}$ & Site class ${ }^{\mathrm{b}}$ & $\begin{array}{c}\mathrm{PGA}^{\mathrm{c}} \\
\mathrm{g}\end{array}$ & $\begin{array}{l}\mathrm{PGV}^{\mathrm{d}} \\
\mathrm{cm} / \mathrm{s}\end{array}$ \\
\hline $\begin{array}{l}\text { Berkeley, NS (Station 58471) Lawrence Berkeley } \\
\text { Lab, Calif., USA }\end{array}$ & $\begin{array}{l}\text { Loma Prieta } \\
10-17-1989\end{array}$ & 7.1 & 99.0 & $\mathrm{C}$ & 0.117 & 22.0 \\
\hline $\begin{array}{l}\text { Beverly Hills, NS (Station 00013) } 14145 \\
\text { Mulholland Dr., Calif., USA }\end{array}$ & $\begin{array}{l}\text { Northridge } \\
01-17-1994\end{array}$ & 6.1 & 12.7 & $\mathrm{D}$ & 0.443 & 59.3 \\
\hline $\begin{array}{l}\text { El Centro, NS (Station 117) Imperial Valley } \\
\text { Irrigation District, Calif., USA }\end{array}$ & $\begin{array}{l}\text { Imperial Valley } \\
05-18-1940\end{array}$ & 6.9 & 16.9 & $\mathrm{D}$ & 0.348 & 33.2 \\
\hline $\begin{array}{l}\text { El Centro, NS (Station 01335) Imperial Co. } \\
\text { Center Grounds, Calif., USA }\end{array}$ & $\begin{array}{l}\text { Superstition Hills } \\
11-24-1987\end{array}$ & 6.6 & 36.0 & $\mathrm{D}$ & 0.341 & 46.6 \\
\hline $\begin{array}{l}\text { Lake Hughes, N21E (Station 125, File 1) Fire } \\
\text { Station \#78, Calif., USA }\end{array}$ & $\begin{array}{l}\text { San Fernando } \\
02-09-1971\end{array}$ & 7.5 & 31.3 & $\mathrm{C}$ & 0.148 & 18.5 \\
\hline $\begin{array}{l}\text { Lancaster, NS (Station 24475) Fox Airfield } \\
\text { Grounds, Calif., USA }\end{array}$ & $\begin{array}{l}\text { Northridge } \\
01-17-1994\end{array}$ & 6.1 & 66.0 & $\mathrm{D}$ & 0.064 & 5.44 \\
\hline $\begin{array}{l}\text { Los Angeles, NS (Station 24303) Hollywood } \\
\text { Storage Building Grounds, Calif., USA }\end{array}$ & $\begin{array}{l}\text { Northridge } \\
01-17-1994\end{array}$ & 6.1 & 23.0 & $\mathrm{D}$ & 0.231 & 18.2 \\
\hline $\begin{array}{l}\text { Richmond, S10E (Station 58505) City Hall } \\
\text { Parking Lot, Calif., USA }\end{array}$ & $\begin{array}{l}\text { Loma Prieta } \\
10-17-1989\end{array}$ & 7.1 & 108.0 & $\mathrm{D}$ & 0.106 & 14.7 \\
\hline $\begin{array}{l}\text { Santa Barbara, S48E (Station 283) Courthouse, } \\
\text { Calif., USA }\end{array}$ & $\begin{array}{l}\text { Kern County } \\
07-21-1952\end{array}$ & 7.5 & 87.8 & $\mathrm{C}$ & 0.131 & 19.3 \\
\hline $\begin{array}{l}\text { Wrightwood, NS (Station 23590) Jackson Flat, } \\
\text { Calif., USA }\end{array}$ & $\begin{array}{l}\text { Northridge } \\
01-17-1994\end{array}$ & 6.1 & 76.0 & $\mathrm{C}$ & 0.056 & 5.06 \\
\hline
\end{tabular}

${ }^{a}$ Center for Engineering Strong Motion Data, CESMD [24]. Sensors are part of the California Strong Motion Instrumentation Program, CSMIP.

${ }^{\mathrm{b}}$ Based on the classifications of sites in ASCE/SEI 7-10 [20].

${ }^{c}$ PGA: Peak ground acceleration.

dPGV: Peak ground velocity.

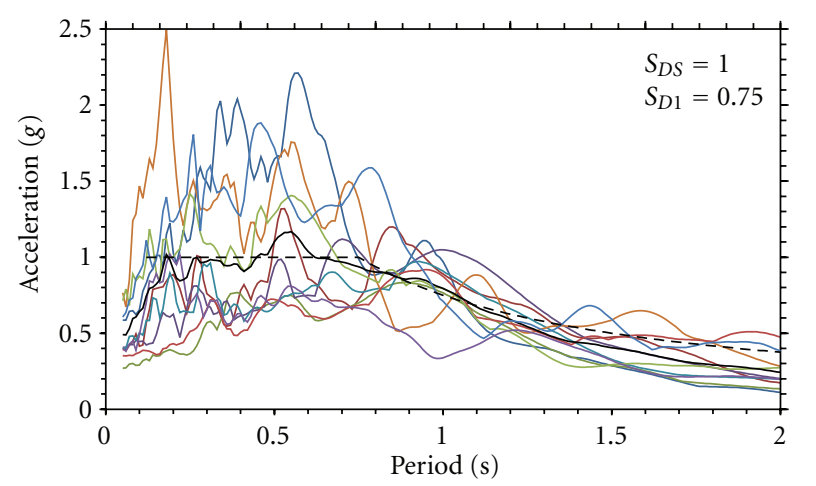

- Average

-- - Idealized

FIGURE 12: Scaled acceleration response spectra.

6.3. Displacement Response Comparison. The calculated maximum displacement will be generally larger for the SDOF systems representing Grade-830 and Grade-670 reinforced structures because of their lower initial and unloading stiffnesses. Figure 13 compares the calculated maximum displacement of the Grade-670 systems with those of the Grade-410 systems when subjected to the suite of 10 earthquake records. The mean for the ratios of the maximum displacement of the Grade-670 systems to the maximum displacement of the Grade-410 systems was 1.13 with a coefficient of variation of 0.13 .

Similarly to Figure 13, the data in Figure 14 show the comparison of calculated displacement maxima of Grade830 systems with those of Grade-410 systems for the same suite of ground motions. The mean for the ratios of the maximum displacement of the Grade- 830 systems to the maximum displacement of the Grade- 410 systems was 1.28 with a coefficient of variation of 0.23 . The ratios reported in Figures 13 and 14 should be considered as upperbound estimates of the increase in displacement demands for moment frames where the reinforcement is replaced with reinforcement of higher grade while maintaining the member cross sections. These estimates were obtained ignoring the effects of initial uncracked stiffness on hysteretic response. Otani [22] has shown that these effects are not always negligible.

Numerical simulations by Rautenberg [8] of multistory concrete frames under strong ground motions have indicated that models of frame buildings with columns reinforced with Grade-830 longitudinal steel and beams reinforced with Grade-410 steel produced roof drifts 1.03 times larger (on average) than the roof drifts computed for models of buildings with columns reinforced with twice as much Grade-410 longitudinal steel. This is because in seismicresistant frames, a relatively larger number of plastic hinges form in the beams than in the columns. Additional studies are underway to evaluate the nonlinear seismic response 


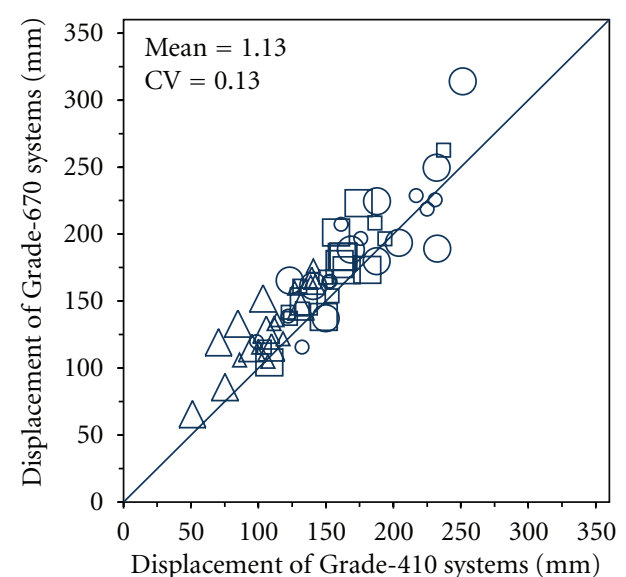

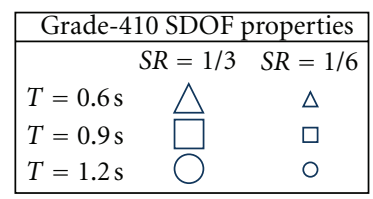

Figure 13: Calculated maximum displacement response, Grade670 versus Grade- 410 systems.

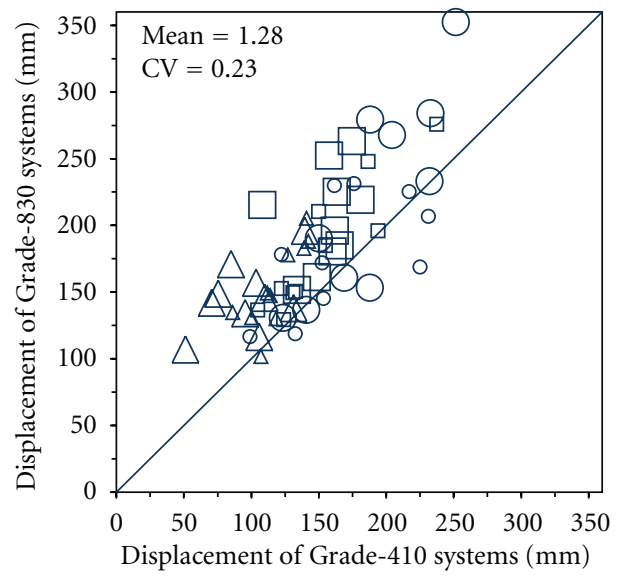

\begin{tabular}{|c|c|c|}
\hline \multicolumn{3}{|c|}{ Grade-410 SDOF properties } \\
\hline & $S R=1 /$ & $=1 / 6$ \\
\hline$T=0.6 \mathrm{~s}$ & & $\Delta$ \\
\hline$T=0.9 \mathrm{~s}$ & & $\square$ \\
\hline$T=1.2 \mathrm{~s}$ & & $\mathrm{O}$ \\
\hline
\end{tabular}

FIGURE 14: Calculated maximum displacement response, Grade830 versus Grade- 410 systems.

of multistory frames where both beams and columns are reinforced with AHSS.

\section{Summary and Conclusions}

Observations on the nonlinear cyclic response of concrete frame members reinforced with advanced high-strength steel (AHSS) are summarized as follows.
(1) Replacing conventional Grade-410 longitudinal reinforcement with reduced amounts of AHSS reinforcement maintained flexural strength and did not decrease the usable member deformation capacity. The tested beams tolerated drift ratios in excess of $10 \%$ without failure while the column specimens tolerated drift ratios of $5 \%$ before failure. Column failures in RC specimens were due to buckling of the longitudinal reinforcement while failures in HPFRC specimens were due to fracture of the longitudinal reinforcement.

(2) Increasing the spacing of Grade-410 transverse reinforcement from $d / 4$ in RC specimens to $d / 2$ in HPFRC specimens, did not reduce the member deformation capacity.

(3) Reducing the amount of longitudinal reinforcement while increasing the yield strength of the reinforcement decreased the postcracking stiffness and increased the yield deformation of the member, leading to a reduction of the area inside the loaddeformation hysteresis loops. Reductions in the amount of longitudinal reinforcement achieved by reducing bar diameter may lead to increased vulnerability to bar buckling.

(4) Nonlinear seismic analyses of SDOF systems with identical strength indicated that the mean ratio of calculated maximum displacements for systems representing RC with AHSS reinforcement to those calculated for RC with conventional Grade-410 reinforcement were about 1.1 for Grade-670 systems and 1.3 for Grade-830 systems.

These observations suggest that AHSS reinforcement is a viable option for frame members in earthquake-resistant construction. Additional studies are needed to investigate the nonlinear seismic response of multistory concrete frames reinforced with AHSS bars.

\section{Abbreviation}

The following symbols are used in the paper:

$A_{g}$ : Gross area of concrete section

$b$ : Width of concrete section

$C_{y}$ : Base shear strength coefficient, ratio of base shear strength to total weight

$d$ : Distance from extreme compression fiber to centroid of longitudinal tension reinforcement

$d_{b}$ : Diameter of reinforcing bar

$D_{\max }$ : Maximum displacement

$D_{y}$ : Yield displacement

$E_{s}$ : Modulus of elasticity of steel, taken as 200,000 MPa (29,000 ksi)

$f_{c}^{\prime}$ : Compressive strength of concrete

$f_{u}$ : Tensile strength of longitudinal reinforcement

$f_{y}$ : Yield strength of longitudinal reinforcement 
$f_{y t}$ : Yield strength of transverse reinforcement

$g$ : Acceleration due to gravity

$h$ : Total depth of concrete section

$k_{p y}$ : Post-yield stiffness

$k_{r}$ : Reloading stiffness

$k_{u}$ : Unloading stiffness

$k_{y}$ : Secant stiffness to yield point

$M_{p r}$ : Probable flexural strength of members, determined using a stress of $1.25 f_{y}$ in the longitudinal bars

$P: \quad$ Applied axial load

$s: \quad$ Center-to-center spacing of transverse reinforcement

$S_{A}: \quad$ Design spectral acceleration, 5\%-damped linear response

$S_{D S}:$ Design spectral acceleration parameter at short periods, 5\%-damped linear response

$S_{D 1}$ : Design spectral acceleration parameter at a period of $1 \mathrm{~s}, 5 \%$-damped linear response

$S R$ : Strength ratio, ratio of base shear strength to 5\%-damped linear-response base shear

T: $\quad$ Period of vibration

$V_{\max }$ : Maximum shear

$V_{y}$ : Yield strength

$\alpha$ : $\quad$ Unloading stiffness coefficient

$\varepsilon_{s u}: \quad$ Fracture strain of reinforcing steel measured in a $203 \mathrm{~mm}$ (8-inch) gage length

$v_{\max }$ : Maximum shear stress, $V_{\max } /(b d)$.

\section{Acknowledgments}

The support provided by The Pennsylvania State University, Concrete Reinforcing Steel Institute, SAS Stressteel Inc., MMFX Technologies Corporation, Bekaert Corporation, Neturen Corporation, and Kenny Construction Company is greatly appreciated.

\section{References}

[1] ACI 318-71, "Building code requirements for reinforced concrete (ACI 318-71)," ACI Standard, American Concrete Institute, Detroit, Mich, USA, 1971.

[2] ACI 318-11, "Building code requirements for structural concrete (ACI 318-11) and commentary," ACI Standard, American Concrete Institute, Farmington Hills, Mich, USA, 2011.

[3] International Iron and Steel Institute, "Advanced High Strength Steel (AHSS) Application Guidelines," 2007, http:// www.worldautosteel.org.

[4] ASTM A1011/A1011M-10, Standard specification for steel, sheet and strip, hot-rolled, carbon, structural, high-strength lowalloy, high-strength low-alloy with improved formability, and ultra-high strength, ASTM International, West Conshohocken, Pa, USA, 2010.

[5] ASTM A1035/A1035M-04, Standard specification for deformed and plain, low-carbon, chromium, steel bars for concrete reinforcement, ASTM International, West Conshohocken, Pa, USA, 2004.
[6] ASTM A706/A706M-09a, Standard specification for low-alloy steel deformed and plain bars for concrete reinforcement, ASTM International, West Conshohocken, Pa, USA, 2009.

[7] H. Tavallali, Cyclic response of concrete beams reinforced with ultrahigh strength steel, Ph.D. thesis dissertation, The Pennsylvania State University, University Park, Pa, USA, 2011.

[8] J. Rautenberg, Drift capacity of concrete columns reinforced with high-strength steel, Ph.D. thesis dissertation, Purdue University, West Lafayette, Ind, USA, 2011.

[9] G. J. Parra-Montesinos, "High-performance fiber-reinforced cement composites: an alternative for seismic design of structures," ACI Structural Journal, vol. 102, no. 5, pp. 668675, 2005.

[10] F. E. Richart and R. L. Brown, "An investigation of reinforced concrete columns," Bulletin 267, Engineering Experiment Station, University of Illinois, Urbana, Ill, USA, 1934.

[11] E. Hognestad, "High strength bars as concrete reinforcement, part 1-introduction to a series of experimental reports," Journal of the PCA Research and Development Laboratories, vol. 3, no. 3, pp. 23-29, 1961.

[12] J. F. Pfister and A. H. Mattock, "High strength bars as concrete reinforcement, part 5-lapped splices in concentrically loaded columns," Journal of the PCA Research and Development Laboratories, vol. 5, no. 2, pp. 27-40, 1963.

[13] C. E. Todeschini, A. C. Bianchini, and C. E. Kesler, "Behavior of concrete columns reinforced with high strength steels," ACI Journal Proceedings, vol. 61, no. 6, pp. 701-715, 1964.

[14] ACI 318-63, "Building code requirements for reinforced concrete (ACI 318-63)," ACI Standard, American Concrete Institute, Detroit, Mich, USA, 1963.

[15] ACI SP-10, "Commentary on building code requirements for reinforced concrete (ACI 318-63)," Standard Building Code, American Concrete Institute, Detroit, Mich, USA, 1965.

[16] W. C. Liao, S. H. Chao, S. Y. Park, and A. E. Naaman, "Self-consolidating high-performance fiber reinforced concrete (SCHPFRC) - preliminary investigation," UMCEE 0602, University of Michigan, Ann Arbor, Mich, USA, 2006.

[17] S. J. Foster, "On behavior of high-strength concrete columns: cover spalling, steel fibers, and ductility," ACI Structural Journal, vol. 98, no. 4, pp. 583-589, 2001.

[18] FEMA 461, Interim Testing Protocols for Determining the Seismic Performance Characteristics of Structural and Nonstructural Components (FEMA 461), Applied Technology Council for the Federal Emergency Management Agency, Washington, DC, USA, 2007.

[19] J. K. Wight and M. A. Sozen, "Strength decay of RC columns under shear reversals," Journal of the Structural Division, vol. 101, no. 5, pp. 1053-1065, 1975.

[20] ASCE/SEI 7-10, "Minimum design loads for buildings and other structures," ASCE Standard, American Society of Civil Engineers, Reston, Va, USA, 2010.

[21] T. Takeda, M. A. Sozen, and M. N. Nielsen, "Reinforced concrete response to simulated earthquakes," Journal of the Structural Division, vol. 96, no. 12, pp. 2557-2573, 1970.

[22] S. Otani, "Hysteresis models of reinforced concrete for earthquake response analysis," Journal of the Faculty of Engineering, vol. 36, no. 2, pp. 125-159, 1981.

[23] N. M. Newmark, "A method of computation for structural dynamics," Journal of the Engineering Mechanics Division, vol. 85, no. 3, pp. 67-94, 1959.

[24] CESMD, “Center for Engineering Strong Motion Data," 2011, http://www.strongmotioncenter.org. 

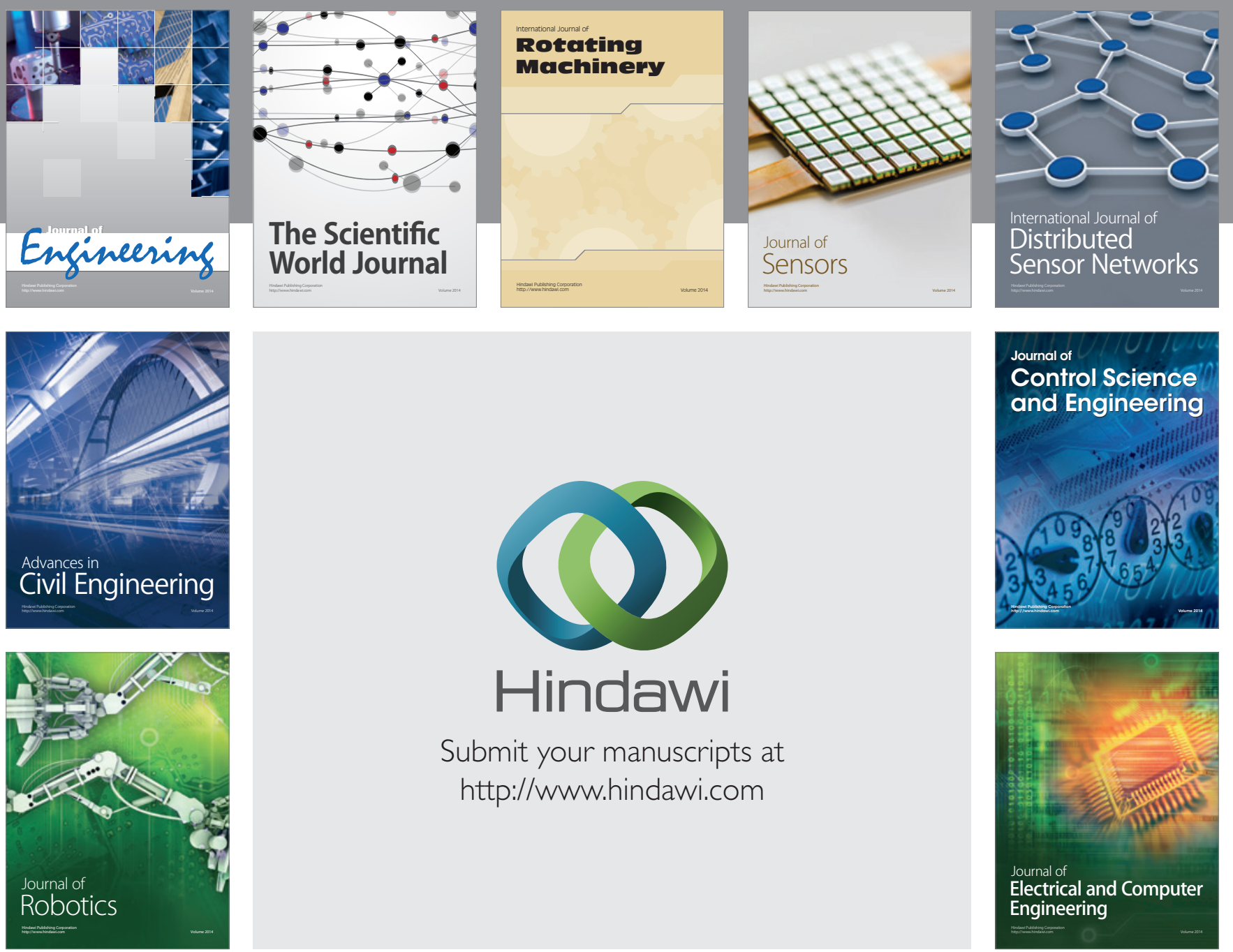

Submit your manuscripts at

http://www.hindawi.com
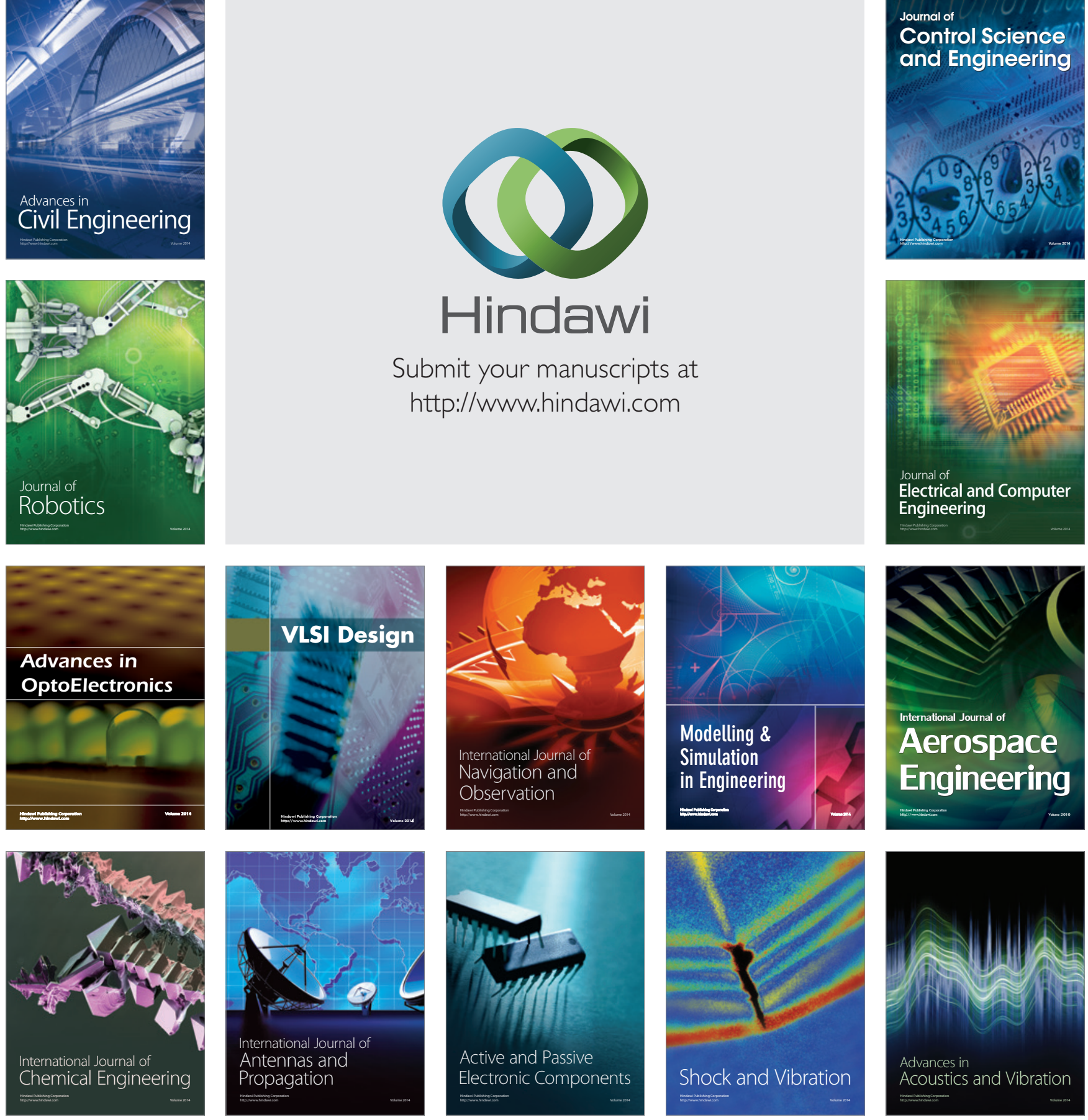